\title{
Consumption of echium oil increases EPA and DPA in blood fractions more efficiently compared to linseed oil in humans
}

\author{
Katrin Kuhnt ${ }^{1 *}$, Stefanie Weiß ${ }^{1}$, Michael Kiehntopf ${ }^{2}$ and Gerhard Jahreis ${ }^{1}$
}

\begin{abstract}
Background: A plant-based strategy to improve long-chain (LC) omega (n)-3 PUFA supply in humans involves dietary supplementation with oils containing a-linolenic acid (ALA) alone or in combination with stearidonic acid (SDA). The study aimed to compare the effects of echium oil (EO) and linseed oil (LO) on LC n-3 PUFA accumulation in blood and on clinical markers.
\end{abstract}

Methods: In two double-blind, parallel-arm, randomized controlled studies, all volunteers started with $17 \mathrm{~g} / \mathrm{d}$ run-in oil (2 weeks). Thereafter, subjects received diets enriched in study 1 with EO (5 g ALA + 2 g SDA; $n=59)$ or in study 2 with LO (5 g ALA; $n=59)$ daily for 8 weeks. The smaller control groups received fish oil $(F O ; n=19)$ or olive oil $(O O ; n=18)$. Participants were instructed to restrict their dietary n-3 PUFA intake throughout the studies (e.g., no fish). To investigate the influence of age and BMI on the conversion of ALA and SDA as well as clinical markers, the subjects recruited for EO and LO treatment were divided into three subgroups (two age groups 20-35 y; 49-69 y with BMI $18-25 \mathrm{~kg} / \mathrm{m}^{2}$ and one group with older, overweight subjects (age $49-69 \mathrm{y} ; \mathrm{BMl}>25 \mathrm{~kg} / \mathrm{m}^{2}$ ).

Results: In plasma, red blood cells (RBC), and peripheral blood mononuclear cells (PBMC), EPA and docosapentaenoic acid (DPA) were $25 \%$ higher following EO compared to LO. Comparing all treatments, the effectiveness of increasing EPA and DPA in plasma, RBC, and PBMC was on average 100:25:10:0 and 100:50:25:0 for FO:EO:LO:OO, respectively. EO led to a lower arachidonic acid/EPA-ratio compared to LO in plasma, RBC, and PBMC. Following EO, final DHA was not greater compared to LO. Higher BMI correlated negatively with increases in plasma EPA and DPA after EO supplementation, but not after LO supplementation. Decreasing effect on plasma LDL-C and serum insulin was greater with $E O$ than with LO.

Conclusions: Daily intake of SDA-containing EO is a better supplement than LO for increasing EPA and DPA in blood. However, neither EO nor LO maintained blood DHA status in the absence of fish/seafood consumption.

Trial registration: ClinicalTrials.gov Reg No. NCT01856179; ClinicalTrials.gov Reg No. NCT01317290.

Keywords: a-linolenic acid, Echium oil, Linseed oil, Stearidonic acid, Eicosapentaenoic acid, Metabolic syndrome

\section{Background}

A high concentration of long-chain (LC) n-3 PUFA in human tissue is associated with a lower risk of cardiovascular disease (CVD) $[1,2]$. Thus, there has been an increasing interest in incorporating $\mathrm{n}-3$ PUFA into the diet. In order to meet dietary eicosapentaenoic acid (20:5n-3; EPA) and docosahexaenoic acid (22:6n-3; DHA) recommendations,

\footnotetext{
*Correspondence: b6jage@uni-jena.de

'Department of Nutritional Physiology, Institute of Nutrition, Friedrich Schiller University, Dornburger Straße 24, 07743 Jena, Germany

Full list of author information is available at the end of the article
}

the American Heart Association recommends consumption of two servings of fish (particularly oily fish) per week [3]. However, the provision of marine LC n-3 PUFA for the (increasing) human population made difficult by problems such as the overfishing and pollution of the marine environment. Further, not everyone eats fish and some people suffer from fish protein allergy. Hence, there is a need to find alternative sources of LC n-3 PUFA for both human nutrition and aquaculture fish feed.

Linseed oil (Linum usitatissimum L.), also known as flaxseed oil, which naturally contains up to $60 \%$ of the 
plant-based $\alpha$-linolenic acid (18:3n-3, ALA), is the essential precursor of LC n-3 PUFA metabolites [4]. Supplementation with linseed oil has previously been shown to increase n-3 PUFA stores in humans. However, conversion of ALA to LC n-3 PUFA is limited and insufficient to achieve adequate tissue levels of EPA. DHA synthesis, in particular, is extremely limited [5-8].

Over the past few years, several novel dietary sources of LC n-3 PUFA for human consumption have been considered [9, 10]. High potential to improve LC n-3 PUFA supply has stearidonic acid (18:4n-3, SDA), another plant-based n-3 PUFA and an intermediate of ALA. SDA is present in high concentrations in some plant families, such as Primulaceae and especially Boraginaceae [11]. Seed oils from echium species (Boraginaceae) are unique due to their high concentrations of SDA and ALA together with $\gamma$-linolenic acid (18:3n-6, GLA) [11]. Oil from Echium plantagineum is an approved novel food available as a food ingredient. In humans, the ability of SDA to increase EPA in blood is higher than that of ALA, presumably because it bypasses the rate-limiting $\Delta 6$-desaturase step [12]. Transgenic SDA-containing soybean (16-28 \% SDA), canola, and linseed oils have been developed $[13,14]$ and recently studied [14-17]. However, genetically modified foods are to date not well accepted by consumers in Europe [9]. Therefore, naturally occurring echium oil and linseed oil were chosen for the present project.

In general, SDA-containing oils possess potent antilipidemic and hepatoprotective effects. Echium oil has been shown to lower serum triglycerides [18-20]. Therefore, it is likely that echium oil may play a role in preventing progression of CVD and type 2 diabetes mellitus.

The primary aim of the entire project including the two present studies was to compare the increase of LC n-3 PUFA in plasma, RBC, and PBMC after consumption of $5 \mathrm{~g}$ ALA $+2 \mathrm{~g}$ SDA from natural echium oil (study 1) compared to only ALA (5 g) from linseed oil (study 2) under the same study conditions. The secondary aim was to investigate the influence of sex, increased age and higher BMI on conversion of ALA and SDA as well as on clinical blood markers. As controls for fatty acid metabolism, n-3 PUFA-poor olive oil (negative control) and EPA-fish oil (positive control) were supplemented throughout the entire project.

\section{Methods}

\section{Ethics statement}

The entire project including two randomized, doubleblind, parallel-arm controlled studies were carried out in accordance with the Declaration of Helsinki of the World Medical Association, approved by the Ethics Committee of the Friedrich Schiller University Jena (No. 2270-04/08) and registered in the Clinical Trials Registry (ClinicalTrials.gov
ID: NCT01856179 and NCT01317290). Written informed consent was obtained from all participants.

\section{Subjects}

The recruitment for echium oil (EO; study $1, \mathrm{n}=60$ ) and linseed oil (LO; study 2, $\mathrm{n}=60$ ) intervention was carried out according to age and BMI in three subgroups (subgroup I: BMI of $18-25 \mathrm{~kg} / \mathrm{m}^{2}, 20-35$ years; subgroup II: BMI of $18-25 \mathrm{~kg} / \mathrm{m}^{2}, 49-69$ years, $\mathrm{n}=20$; and subgroup III: overweight subjects, BMI $>25 \mathrm{~kg} / \mathrm{m}^{2}$ ) (Fig. 1). Only normal-weight subjects in two age subgroups $(20-35$ y and $49-69$ y) were recruited for the smaller control groups: fish oil (FO, positive control, study $1, \mathrm{n}=20$ ) and olive oil $(\mathrm{OO}$, negative control, study $2, \mathrm{n}=20)$. Gender was balanced in all groups. Recruitment of participants for the fish oil and echium oil interventions in study 1 (2011) has been described previously [20].

The subjects from study 1 were asked to participate in the subsequent study 2 (2012) to increase comparability. Former EO subjects were allocated to supplementation with $\mathrm{LO}$, while former FO subjects were allocated to $\mathrm{OO}$ supplementation. In total, $80 \%$ of the older subjects and $50 \%$ of the younger subjects participated again in study 2 . Exclusion criteria for both studies included: vegetarianism, veganism, daily alcohol abuse, pregnancy, lactation, chronic diseases, use of blood pressure-, cholesterol-, or TGlowering medications or dietary supplements.

\section{Experimental design and diets}

The two studies were performed according to same conditions (design, diets and analytical methods) as previously published $[20,21]$. The same investigator and technical staff conducted both studies. Both studies started with a 2-weeks run-in period, in which all enrolled subjects (each $\mathrm{n}=80$ ) consumed $17 \mathrm{~g} / \mathrm{d}$ of the same run-in oil. After that, subjects received the oil treatment for 8 weeks. In study 1 , two thirds were randomly allocated to receive EO ( $\mathrm{n}=20$ per subgroup) and one third was randomly allocated to FO ( $\mathrm{n}=10$ per subgroup). In study 2, the newly recruited subjects were also randomly allocated to receive LO ( $\mathrm{n}=20$ per subgroups I\& II) and to OO ( $\mathrm{n}=10$ per subgroups I\&II).

Thus, in study 1 comprised EO $(n=60)$ and FO $(n=20)$ and in study 2 comprised LO $(n=60)$ and OO $(n=20)$ (Fig. 1). In order to reduce dietary intake of additional n-3 PUFA and linoleic acid (18:2n-6; LA) during the 10-week study, the participants were encouraged to avoid consuming the following foods: fish, fish oils, seafood, n-3 PUFA-rich foods, linseed and rapeseed oil, as well as margarine and common LA-rich sunflower oil. To reduce variation in dietary FA intake before blood sampling at day 0 and day 56 , all volunteers received a defined diet for three successive days as described previously [20,22]. 


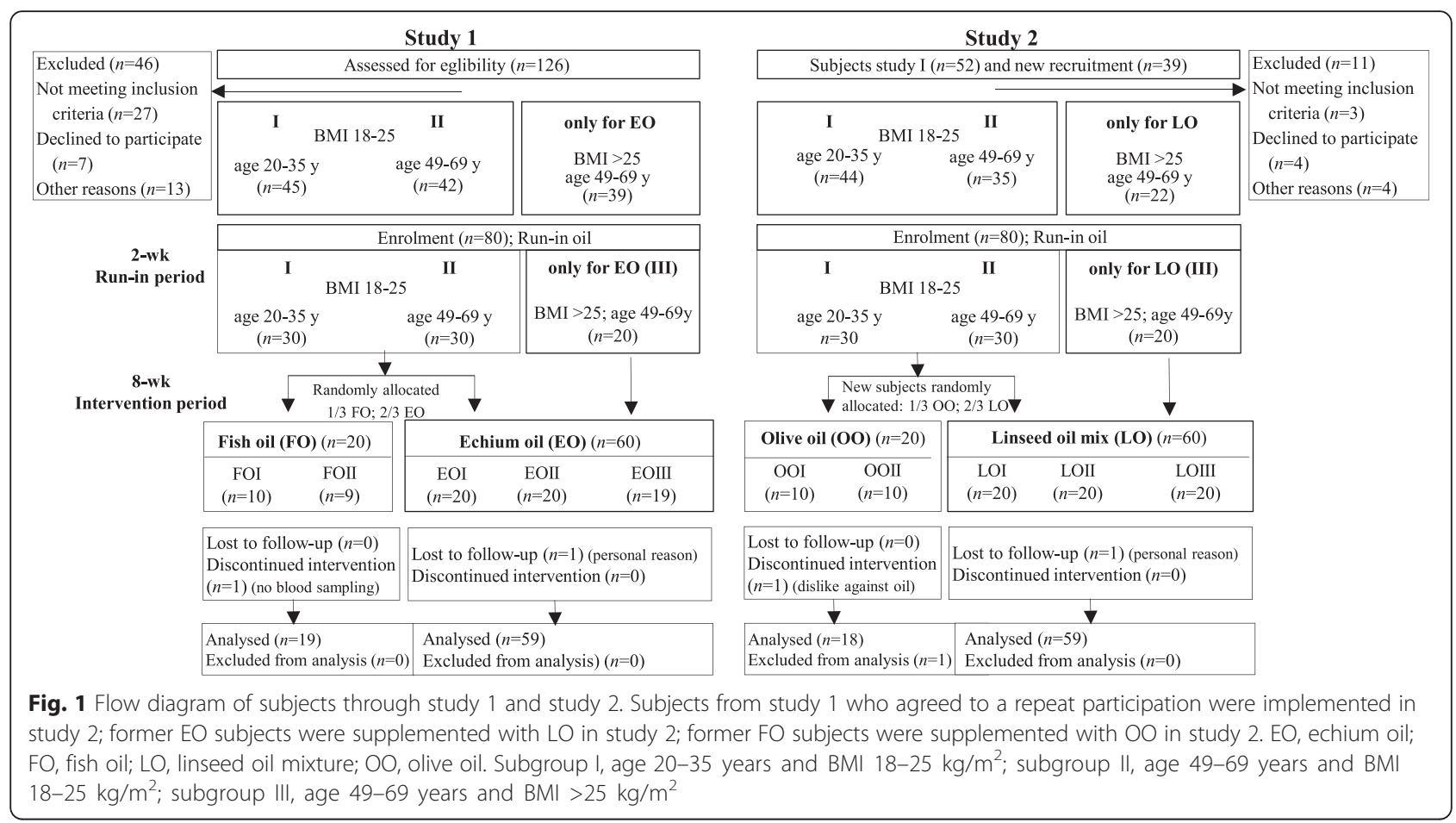

\section{Supplemented oils}

The run-in oil in both studies contained a mixture of fats and oils [20, 21] to represent the FA distribution of the Western diet. All four treatment groups received approximately $17 \mathrm{~g} / \mathrm{d}$ of the respective study oil (Table 1 ). To balance the fat intake, also $17 \mathrm{~g}$ of run-in oil were supplemented in the first 2 weeks (run-in period) (Fig. 1; Table 1). The EO subjects received EO (seed oil of $E$. plantagineum, INCROMEGA V3, Croda; two tablespoons) containing an average of $5 \mathrm{~g}$ ALA, $2 \mathrm{~g}$ SDA and 2 g GLA (Table 1). The LO subjects were supplemented with 5 g ALA from linseed oil (Erfurter Ölmühle) [21].

Table 1 FA profile and daily FA dose with run-in oil and with treatment oils ${ }^{\mathrm{a}}$

\begin{tabular}{|c|c|c|c|c|c|c|c|c|c|c|}
\hline \multirow{4}{*}{ Treatment } & \multirow{3}{*}{\multicolumn{2}{|c|}{$\frac{\text { Run-in period ( } 2 \text { weeks) }}{\text { Run-in oil }(n=155)}$}} & \multicolumn{8}{|c|}{ Intervention period (8 weeks) } \\
\hline & & & \multirow{2}{*}{\multicolumn{2}{|c|}{$\begin{array}{l}\text { Echium oil (study 1) } \\
(n=59)\end{array}$}} & \multirow{2}{*}{\multicolumn{2}{|c|}{$\begin{array}{l}\text { Linseed oil mixture } \\
\text { (study 2) }(n=59)\end{array}$}} & \multicolumn{4}{|c|}{ Control groups } \\
\hline & & & & & & & \multicolumn{2}{|c|}{$\begin{array}{l}\left.\text { Fish oil }{ }^{\mathrm{b}} \text { (study } 1\right) \\
(n=19)\end{array}$} & \multicolumn{2}{|c|}{$\begin{array}{l}\text { Olive oil (study } 2 \\
(n=18)\end{array}$} \\
\hline & $\%$ & $g / d$ & $\%$ & $g / d$ & $\%$ & $g / d$ & $\%$ & $g / d$ & $\%$ & $g / d$ \\
\hline Oil dose & & 17 & & 17 & & 17 & & 17 & & 17 \\
\hline \multicolumn{11}{|c|}{ FA groups and individual FA } \\
\hline ¿SFA & 44 & 7.5 & 11 & 1.8 & 9.0 & 1.4 & 12 & 2.1 & 14 & 2.1 \\
\hline ¿MUFA (mainly 18:1n-9) & 39 & 6.7 & 18 & 3.0 & 38 & 5.9 & 66 & 12 & 80 & 12 \\
\hline ¿PUFA & 16 & 2.8 & 70 & 12 & 53 & 8.1 & 22 & 3.3 & 6.0 & 0.9 \\
\hline 18:2n-6, LA & 16 & 2.8 & 17 & 2.9 & 22 & 3.3 & 5.7 & 0.9 & 5.5 & 0.8 \\
\hline 18:3n-6, GLA & - & - & 11 & 1.8 & - & - & 0.1 & - & - & - \\
\hline 18:3n-3, ALA & 0.2 & - & 30 & 5.0 & 31 & 4.9 & 0.6 & 0.1 & 0.5 & 0.1 \\
\hline $18: 4 n-3$, SDA & - & - & 12 & 2.0 & - & - & 1.2 & 0.2 & - & - \\
\hline 20:5n-3, EPA & - & - & - & - & - & - & 11 & 1.9 & - & - \\
\hline $22: 5 n-3$, DPA & - & - & - & - & - & - & 0.2 & - & - & - \\
\hline 22:6n-3, DHA & - & - & - & - & - & - & 1.4 & 0.2 & - & - \\
\hline$n-6 / n-3$ & $80 / 1$ & & $0.7 / 1$ & & $0.7 / 1$ & & $0.4 / 1$ & & $11 / 1$ & \\
\hline
\end{tabular}


The linseed oil was blended with common sunflower oil and a plant oil mixture (K-Classic) to obtain similar ALA dosage, $n-6 / n-3$ ratio and LA content as in EO [16], (Table 1). The control groups received EPA-rich FO as positive control (1.9 g/d EPA; CRODA EPA-TG500 ) or highly refined OO as n-3 PUFA-poor negative control (Gustav Heess). Female subjects received a slightly smaller quantity of study oil than male participants (15.5 g/d vs. $18.5 \mathrm{~g} / \mathrm{d}$ ) [20]; to provide comparable amounts of ALA ( $\sim 2 \%$ of total energy intake) for both genders. The handling of study oils and blinding was similar as previously stated $[20,21]$.

\section{Blood sampling}

Blood was collected at the Institute of Nutrition in Jena following the 2-weeks run-in period (day 0), and after 7 and 56 days of oil supplementation. Blood sampling methods and for preparation of blood fractions such as plasma, RBC, and peripheral blood mononuclear cells (PBMC) were described previously [20-22].

\section{Biochemical markers}

Total cholesterol (TC), HDL-C, LDL-C, and TG (enzymatic colorimetric), oxLDL (ELISA), high sensitivity C-reactive protein and lipoprotein (a) (immunoturbidimetric), insulin (immunochemiluminometric) were analyzed according to the methods of the Institute of Clinical Chemistry and Laboratory Medicine at Jena University Hospital [20].

\section{Anthropometric parameters}

Waist circumference, blood pressure, body composition (50 kHz-frequency impedance analyzer; Data Input) and body weight were recorded after the run-in period (day 0 ) and intervention period (day 56).

\section{Fatty acid analysis}

Preparation of plasma, $\mathrm{RBC}$, and $\mathrm{PBMC}$ fractions, and lipid extraction with chloroform/methanol/water (2:1:1, $\mathrm{v}: v: v)$ were performed as described by Kuhnt et al. [20-22]. In brief, FA were methylated with methanolic boron trifluoride into fatty acid methyl esters (FAME). Following purification by thin layer chromatography, FAME were analyzed by gas chromatography (GC) with flame ionization detector $(60 \mathrm{~m}$ column length; DB225MS, Agilent Technologies). In all analyzed blood fractions, the same $47 \mathrm{FA}$ were integrated (C10-C24). Individual FAME were expressed as a percentage of total identified FAME peak areas [\% of total $(\Sigma)$ FAME]. Samples were blinded during FA analysis. The reference standards used as FAME included: No. 463, 674 (Nu-Check Prep), BR2, BR4, ME93 (Larodan), Supelco 37 Component FAME Mix (Supelco) and PUFA No.3 (Matreya LLC). LabSolutions was used for GC peak integration (Shimadzu).

\section{Statistical analysis}

All statistical analyses were performed using SPSS software 19.0. (IBM Corporation). The results are stated as means \pm SD unless otherwise noted. The treatment effects on FA and biochemical markers were analyzed using the linear mixed model. Each variable was evaluated using analysis of covariance (ANCOVA) with sex, age, BMI, and the respective baseline value as covariates. Oil treatment as a factor for main effects and sex, age, and BMI as factors for interaction, were included in order to control type I. The differences between subgroup characteristics within and between treatments at baseline (day 0) were analyzed using subgroups as fixed factors without covariates (ANOVA). To examine the effect of time (day 0 to day 56) for total subjects of each treatment, repeated measures ANCOVA was used. In general, the $P$ values of the pairwise comparisons were stated and were adjusted by using the stepdown Bonferroni method. Pearson correlation analyses were conducted to test associations. Statistical significance was set at $P \leq 0.05$ for all analyses.

\section{Results}

\section{Characteristics of subjects}

In the subgroups II and III with higher age and BMI, anthropometric measures and clinical markers were generally greater (except HDL-C) (Table 2). Weight gain, waist circumference, BMI, and portion of body fat did not differ between EO and LO treatments (data not shown).

\section{Fatty acid composition in blood fractions Run-in period}

Following the run-in period, of those who completed the study $(n=154)$, women had a lower plasma docosapentaenoic acid (22:5n-3, DPA) but a higher plasma DHA than men $(P \leq 0.001)$. Age was positively correlated with plasma EPA, DPA, and DHA ( $\mathrm{r}=0.538,0.388,0.279$; $P \leq 0.001$, respectively). BMI was also positively correlated with plasma EPA and DPA $(\mathrm{r}=0.262, P \leq 0.001 ; \mathrm{r}=0.172, P=0.033)$ but not with plasma DHA $(\mathrm{r}=0.12, P=0.13)$.

\section{Intervention period}

Following 8 weeks of EO and LO supplementation, significant increases in ALA, SDA and the LC n-3 PUFA metabolites eicosatetraenoic acid (20:4n-3; ETA) EPA, and DPA were found in plasma, RBC, and PBMC $(P<0.01$; Table 3$)$. However, in all blood fractions the increase in ETA, EPA, and DPA were approximately $40-60 \%$ higher with EO than with LO. In general, the greatest increase of ETA, EPA and DPA were found in plasma, followed by PBMC and RBC (Table 3). Final EPA and DPA in plasma, RBC, and $\mathrm{PBMC}$ were consistently higher (15-35 \%) compared to LO, respectively $(P<0.05$; Table 4$)$. DHA did not accumulate with $\mathrm{EO}$ or LO and instead decreased in plasma, 
Table 2 Characteristics of the study subgroups following the run-in period (day 0), prior to receiving echium oil or linseed oil mixture

\begin{tabular}{|c|c|c|c|c|c|c|}
\hline \multirow[b]{2}{*}{ Subgroups } & \multicolumn{3}{|c|}{ Study 1 Echium oil } & \multicolumn{3}{|c|}{ Study 2 Linseed oil mixture } \\
\hline & $\mathrm{EOI}(n=20)$ & EOII $(n=20)$ & EOIII $(n=19)$ & LOI $(n=20)$ & LOII $(n=20)$ & LOIII $(n=19)$ \\
\hline Sex, f/m & $10 / 10$ & $11 / 9$ & $9 / 10$ & $10 / 10$ & $10 / 10$ & $10 / 9$ \\
\hline BMl group $\left(\mathrm{kg} / \mathrm{m}^{2}\right)$ & $18-25$ & $18-25$ & $>25$ & $18-25$ & $18-25$ & $>25$ \\
\hline Age group (years) & $20-35$ & $49-69$ & $49-69$ & $20-35$ & $49-69$ & $49-69$ \\
\hline Repeated participation (\%) & & & & 40 & 90 & 80 \\
\hline Age (years) & $28.1 \pm 2.86^{\mathrm{b}}$ & $58.8 \pm 5.73^{a}$ & $61.2 \pm 6.26^{\mathrm{a}}$ & $25.0 \pm 3.43^{b}$ & $59.0 \pm 5.56^{\mathrm{a}}$ & $61.1 \pm 7.28^{\mathrm{a}}$ \\
\hline Body mass index $\left(\mathrm{kg} / \mathrm{m}^{2}\right)$ & $22.0 \pm 2.34^{b}$ & $23.5 \pm 2.40^{b}$ & $30.1 \pm 3.30^{\mathrm{a}}$ & $22.3 \pm 2.24^{b}$ & $23.2 \pm 2.27^{b}$ & $29.5 \pm 3.26^{a}$ \\
\hline Waist circumference $(\mathrm{cm})$ & $80.3 \pm 9.10^{c}$ & $87.2 \pm 9.17^{b}$ & $104 \pm 6.75^{a \ddagger}$ & $80.7 \pm 4.95^{c}$ & $86.3 \pm 7.71^{b}$ & $99.4 \pm 7.19^{\mathrm{a}}$ \\
\hline Systolic BP (mm Hg) & $125 \pm 10.4^{\mathrm{b}^{*}}$ & $135 \pm 19.9^{\mathrm{ab}}$ & $141 \pm 15.6^{\mathrm{a} \neq}$ & $133 \pm 17.3^{b}$ & $148 \pm 20.2^{b}$ & $154 \pm 24.0^{\mathrm{a}}$ \\
\hline Diastolic BP (mm Hg) & $82.2 \pm 8.9^{b}$ & $90.1 \pm 12.3^{\mathrm{a}}$ & $91.2 \pm 7.90^{\mathrm{a}}$ & $82.4 \pm 6.68^{\mathrm{a}}$ & $89.5 \pm 10.7^{\mathrm{a}}$ & $85.3 \pm 19.8^{\mathrm{a}}$ \\
\hline Total cholesterol (mmol/L) & $4.52 \pm 0.68^{b}$ & $5.82 \pm 1.24^{\mathrm{a}}$ & $6.30 \pm 1.02^{\mathrm{a}}$ & $4.43 \pm 0.80^{b}$ & $5.58 \pm 1.32^{\mathrm{a}}$ & $5.84 \pm 1.09^{\mathrm{a}}$ \\
\hline $\mathrm{HDL}-\mathrm{C}(\mathrm{mmol} / \mathrm{L})$ & $1.43 \pm 0.30^{a}$ & $1.58 \pm 0.47^{\mathrm{a}}$ & $1.33 \pm 0.32^{\mathrm{a}}$ & $1.39 \pm 0.27^{\mathrm{a}}$ & $1.44 \pm 0.38^{\mathrm{a}}$ & $1.30 \pm 0.33^{\mathrm{a}}$ \\
\hline LDL-C (mmol/L) & $2.54 \pm 0.61^{b}$ & $3.54 \pm 0.89^{\mathrm{a}}$ & $3.95 \pm 0.90^{\mathrm{a}}$ & $2.48 \pm 0.75^{b}$ & $3.36 \pm 0.98^{\mathrm{a}}$ & $3.70 \pm 0.97^{\mathrm{a}}$ \\
\hline LDL-C/HDL-C & $1.87 \pm 0.67^{b}$ & $2.37 \pm 0.66^{b}$ & $3.08 \pm 0.75^{\mathrm{a}}$ & $1.86 \pm 0.70^{b}$ & $2.42 \pm 0.70^{a}$ & $2.90 \pm 0.83^{\mathrm{a}}$ \\
\hline Triglycerides (mmol/L) & $0.89 \pm 0.36^{b}$ & $1.14 \pm 0.42^{b}$ & $1.82 \pm 0.88^{a \neq}$ & $0.97 \pm 0.39^{\mathrm{a}}$ & $1.31 \pm 0.94^{\mathrm{a}}$ & $1.39 \pm 0.51^{a}$ \\
\hline Oxidized LDL (mmol/L) & $67.7 \pm 12.7^{c^{*}}$ & $80.3 \pm 11.4^{b^{*}}$ & $92.9 \pm 13.2^{\mathrm{a}^{*}}$ & $49.9 \pm 18.0^{b}$ & $60.8 \pm 15.2^{\mathrm{a}}$ & $66.6 \pm 14.2^{\mathrm{a}}$ \\
\hline High sensitivity CRP (mg/L) & $0.68 \pm 0.62^{a}$ & $1.35 \pm 2.03^{\mathrm{a}}$ & $2.12 \pm 2.41^{a}$ & $1.32 \pm 1.60^{\mathrm{a}}$ & $1.25 \pm 1.50^{\mathrm{a}}$ & $1.64 \pm 1.43^{\mathrm{a}}$ \\
\hline Insulin (mU/L) & $6.03 \pm 2.35^{b}$ & $9.75 \pm 5.90^{\mathrm{a}}$ & $11.6 \pm 4.77^{\mathrm{a}}$ & $6.22 \pm 2.57^{b}$ & $7.96 \pm 4.92^{\mathrm{a}}$ & $10.8 \pm 6.78^{a}$ \\
\hline
\end{tabular}

${ }^{1}$ Values are means \pm SD. C cholesterol. EO echium oil, LO linseed oil mixture; I, age 20-35 years and BMI $18-25 \mathrm{~kg} / \mathrm{m}^{2} ; \mathrm{II}$, age $49-69$ years and BMI $18-25 \mathrm{~kg} / \mathrm{m}^{2} ; \mathrm{III}$, age $49-69$ years and $\mathrm{BMI}>25 \mathrm{~kg} / \mathrm{m}^{2}$. $P$ values were analyzed using the generalized linear mixed model ANOVA

abc Within one oil treatment, means within a row with different superscript letters are significantly different between subgroups $(P \leq 0.05)$

${ }^{*}$ Mean values are significantly different between the respective EO and LO subgroups (I, II, III) $\left({ }^{*} P \leq 0.05,{ }^{\ddagger} P 0.05<0.10\right)$

$\mathrm{RBC}$, and PBMC; however, the decrease in plasma was lower with EO vs. LO $(P=0.008)$ (Table 3). The final plasma DHA was higher with EO compared to LO, but lower in PBMC $(P<0.01$; Table 4$)$.

Considering all treatments, increases in plasma, RBC, and PBMC of EPA were highest with FO $(\sim 520 \%)$, followed by EO ( 117 \%), LO ( 48 \%), and OO ( 0 \%, $P<0.001$; Table 3$)$. The increase in plasma, $\mathrm{RBC}$, and PBMC DPA was also significantly the highest with FO (94\%), but with a lower distance to EO (47\%), LO (23\%), and OO (0 \%; Table 3). Overall, final EPA and DPA in plasma, $\mathrm{RBC}$ and $\mathrm{PBMC}$ were in similar order: $\mathrm{FO}>\mathrm{EO}>\mathrm{LO}>\mathrm{OO} \quad(P \leq 0.001$; not for DPA in $\mathrm{RBC}$; Table 4). In plasma and PBMC, DHA was highest following $\mathrm{FO}$, but was not different in $\mathrm{RBC}$ compared to EO or LO (Table 4).

With respect to n-6 PUFA, EO supplementation increased GLA in plasma, RBC, and PBMC and was greatest compared to the remaining oil treatments (Table 3). In addition, DGLA and AA (the LC metabolites of GLA) also increased in all blood fractions, except for AA in PBMC (Table 4). Therefore, in all blood fractions, final GLA and DGLA were the highest with EO $(P<0.001$; data not shown). The ratio of AA/EPA in plasma, RBC, and PBMC was lowest with FO compared to EO vs. LO vs. OO $(P<0.001$; Fig. 2$)$. The final AA/EPA ratio in plasma and PBMC was lower $(P<0.001)$ with EO vs. LO, but in RBC only as a trend $(P=0.09$; Fig. 2$)$.

In subjects consuming EO, BMI was negatively correlated with the relative increase in plasma EPA and DPA. In subjects consuming LO, there were no correlations to $\mathrm{BMI}$ in line with the non-interaction with BMI (data not shown).

\section{Effects on clinical markers}

Correlations between age, BMI, anthropometrical and biochemical markers reflect differences in baseline characteristics between age and BMI subgroups (Table 2).

Change in HDL-C was clearly contrasting between EO and LO (Table 5), HDL-C decreased with EO, but increased with LO. Therefore, final HDL-C was lower with EO vs. LO (Table 5). The LDL-C decrease was greater with EO vs. LO. Finally, HDL-C/LDL-C ratio was lower with LO vs. EO. Plasma concentration of TC and TG decreased with EO, but final values did not differ between EO and LO (Table 5).

In the control groups, FO showed the strongest TG reduction $(-17 \%)$, while TG increased with $\mathrm{OO}(+10 \%$; data not shown). The serum concentration of oxLDL decreased with both EO and LO; however, the significant difference between final oxLDL in the EO and LO groups (Table 5) was due to the significantly lower baseline values 
Table 3 Percent change of FA in plasma, RBC, and PBMC in echium oil vs. linseed oil groups and in control groups after 8-weeks treatment ${ }^{1}$

\begin{tabular}{|c|c|c|c|c|c|c|}
\hline \multicolumn{2}{|c|}{ Change of FA, \% } & \multirow{2}{*}{$\begin{array}{l}\text { Study } 1 \text { Echium } \\
\text { oil }(n=59)\end{array}$} & \multirow{2}{*}{$\begin{array}{l}\text { Study } 2 \text { Linseed oil } \\
\text { mixture }(n=59)\end{array}$} & \multirow{2}{*}{$\begin{array}{l}\text { Treatment effect } \\
\text { EO vs. LO P }\end{array}$} & \multicolumn{2}{|l|}{ Control groups } \\
\hline & & & & & Fish oil $(n=19)$ & Olive oil $(n=18)$ \\
\hline \multicolumn{7}{|l|}{ Plasma } \\
\hline \multirow[t]{6}{*}{ n-3 PUFA } & ALA & $230 \pm 13^{b t}$ & $314 \pm 20^{\text {at }}$ & 0.001 & $-8 \pm 4^{c}$ & $14 \pm 5^{c \dagger}$ \\
\hline & SDA & $789 \pm 69^{\text {a† }}$ & $159 \pm 13^{\mathrm{bt}}$ & $<0.001$ & $59 \pm 19^{\mathrm{bt}}$ & $22 \pm 14^{b}$ \\
\hline & ETA & $406 \pm 32^{\text {a† }}$ & $124 \pm 10^{\mathrm{bt}}$ & $<0.001$ & $53 \pm 12^{\mathrm{bt}}$ & $27 \pm 10^{\mathrm{bt}}$ \\
\hline & EPA & $168 \pm 8^{\mathrm{b} \dagger}$ & $67 \pm 6^{c+}$ & $<0.001$ & $646 \pm 75^{\text {at }}$ & $4 \pm 6^{d}$ \\
\hline & DPA & $68 \pm 4^{\mathrm{bt}}$ & $31 \pm 3^{\mathrm{ct}}$ & $<0.001$ & $113 \pm 13^{\text {at }}$ & $-1 \pm 2^{d}$ \\
\hline & DHA & $-3 \pm 3^{b}$ & $-11 \pm 2^{\mathrm{b} t}$ & 0.008 & $39 \pm 8^{\text {at }}$ & $-5 \pm 3^{b}$ \\
\hline \multirow[t]{5}{*}{ n-6 PUFA } & LA & $-9 \pm 1^{\mathrm{bt}}$ & $3 \pm 1^{\text {at }}$ & $<0.001$ & $-13 \pm 2^{b \dagger}$ & $-8 \pm 1^{\mathrm{bt}}$ \\
\hline & GLA & $276 \pm 23^{\text {at }}$ & $-11 \pm 3^{\mathrm{bt}}$ & $<0.001$ & $-16 \pm 4^{\mathrm{bt}}$ & $7 \pm 6^{b}$ \\
\hline & DGLA & $67 \pm 5^{\text {at }}$ & $-10 \pm 2^{\mathrm{bct}}$ & $<0.001$ & $-26 \pm 4^{\mathrm{ct}}$ & $6 \pm 3^{b}$ \\
\hline & $\mathrm{AA}$ & $14 \pm 2^{\text {a† }}$ & $-1 \pm 2^{b}$ & $<0.001$ & $3 \pm 3^{\mathrm{ab}}$ & $0 \pm 3^{b}$ \\
\hline & $22: 5 n-6$ & $-20 \pm 3^{\mathrm{bt}}$ & $-9 \pm 3^{b+}$ & 0.006 & $-38 \pm 7^{\mathrm{bt}}$ & $12 \pm 5^{\mathrm{a}}$ \\
\hline \multicolumn{7}{|l|}{$\mathrm{RBC}$} \\
\hline \multirow[t]{6}{*}{ n-3 PUFA } & ALA & $156 \pm 32^{\mathrm{bt}}$ & $201 \pm 9^{\text {at }}$ & $<0.001$ & $-12 \pm 5^{c}$ & $8 \pm 3^{c+}$ \\
\hline & SDA & $405 \pm 54^{\text {a† }}$ & $135 \pm 22^{\mathrm{bt}}$ & $<0.001$ & $6 \pm 13^{c}$ & $49 \pm 35^{b}$ \\
\hline & ETA & $243 \pm 22^{\text {a† }}$ & $106 \pm 7^{\mathrm{bt}}$ & $<0.001$ & $24 \pm 6^{c}$ & $9 \pm 4^{c}$ \\
\hline & EPA & $85 \pm 12^{\mathrm{bt}}$ & $32 \pm 4^{\mathrm{ct}}$ & $<0.001$ & $351 \pm 35^{\mathrm{a}+}$ & $-10 \pm 3^{\mathrm{dt}}$ \\
\hline & DPA & $32 \pm 8^{\mathrm{bt}}$ & $12 \pm 2^{\mathrm{ct}}$ & $<0.001$ & $75 \pm 16^{\mathrm{a}+}$ & $-4 \pm 2^{d}$ \\
\hline & DHA & $-4 \pm 2^{\mathrm{b} \dagger}$ & $-10 \pm 2^{\mathrm{bt}}$ & 0.15 & $10 \pm 9^{a}$ & $-9 \pm 2^{\mathrm{b} \dagger}$ \\
\hline \multirow[t]{5}{*}{ n-6 PUFA } & LA & $11 \pm 3^{a}$ & $1 \pm 1^{b}$ & $<0.001$ & $-11 \pm 4^{b}$ & $-4 \pm 1^{\mathrm{bt}}$ \\
\hline & GLA & $144 \pm 16^{\text {a† }}$ & $0 \pm 4^{b}$ & $<0.001$ & $1 \pm 2^{b}$ & $7 \pm 6^{b}$ \\
\hline & DGLA & $48 \pm 9^{\text {at }}$ & $-5 \pm 1^{\mathrm{bt}}$ & $<0.001$ & $-15 \pm 3^{b}$ & $3 \pm 1^{b}$ \\
\hline & AA & $17 \pm 3^{a+}$ & $-1 \pm 1^{b}$ & $<0.001$ & $2 \pm 4^{b}$ & $0 \pm 1^{b}$ \\
\hline & $22: 5 n-6$ & $-2 \pm 4^{\mathrm{a}}$ & $-4 \pm 1^{\text {at }}$ & 0.43 & $-29 \pm 5^{\mathrm{b} t}$ & $6 \pm 2^{a}$ \\
\hline \multicolumn{7}{|l|}{ PBMC } \\
\hline \multirow[t]{6}{*}{ n-3 PUFA } & ALA & $147 \pm 20^{\mathrm{bt}}$ & $368 \pm 28^{\mathrm{a} \dagger}$ & $<0.001$ & $70 \pm 43^{b c}$ & $13 \pm 8^{c}$ \\
\hline & SDA & $424 \pm 78^{\mathrm{a} \dagger}$ & $103 \pm 34^{b}$ & $<0.001$ & $-2 \pm 24^{b}$ & $47 \pm 45^{b}$ \\
\hline & ETA & $388 \pm 35^{a^{+\dagger}}$ & $81 \pm 5^{\mathrm{b} t}$ & $<0.001$ & $38 \pm 6^{\mathrm{b} \dagger}$ & $27 \pm 19^{b}$ \\
\hline & EPA & $97 \pm 9^{\mathrm{bt}}$ & $45 \pm 5^{c \dagger}$ & 0.005 & $564 \pm 57^{\mathrm{a}+}$ & $-1 \pm 4^{d}$ \\
\hline & DPA & $42 \pm 5^{\mathrm{bt}}$ & $27 \pm 2^{c \dagger}$ & 0.006 & $94 \pm 8^{\text {a }}$ & $3 \pm 2^{c}$ \\
\hline & DHA & $-20 \pm 3^{\mathrm{bt}}$ & $-15 \pm 1^{\mathrm{bt}}$ & 0.12 & $2 \pm 5^{a}$ & $-4 \pm 2^{\mathrm{ab}}$ \\
\hline \multirow[t]{5}{*}{ n-6 PUFA } & LA & $8 \pm 2^{\mathrm{a}}$ & $5 \pm 1^{a}$ & 0.42 & $6 \pm 3^{a}$ & $-7 \pm 2^{\mathrm{b} t}$ \\
\hline & GLA & $128 \pm 14^{\mathrm{a}+}$ & $-1 \pm 4^{b}$ & $<0.001$ & $12 \pm 15^{b}$ & $7 \pm 4^{b}$ \\
\hline & DGLA & $47 \pm 17^{\text {at }}$ & $-1 \pm 1^{\mathrm{b} t}$ & $<0.001$ & $-15 \pm 3^{\mathrm{b} t}$ & $6 \pm 2^{b}$ \\
\hline & AA & $-2 \pm 3^{a}$ & $-2 \pm 1^{\text {at }}$ & 0.92 & $-10 \pm 2^{\mathrm{b} \dagger}$ & $2 \pm 1^{a}$ \\
\hline & $22: 5 n-6$ & $-17 \pm 6^{\text {at }}$ & $-8 \pm 2^{\mathrm{a} \dagger}$ & 0.17 & $-48 \pm 3^{b t}$ & $8 \pm 4^{a}$ \\
\hline
\end{tabular}

${ }^{1}$ Values are means \pm SEM; adjusted means not shown. Change is from day 0 to day 56 . EO echium oil, ETA 20:4n-3, eicosatetraenoic acid, $L O$ linseed oil mixture, $R B C$ red blood cells, $P B M C$ peripheral blood mononuclear cells. $P$ values were analyzed using the generalized linear mixed model ANCOVA with sex, age, BMI, baseline value as covariates

${ }^{2} P$ values for the treatment effect including only EO and LO groups

${ }^{\mathrm{abc}}$ Means with different superscript letters are significantly different between all treatments $(P \leq 0.05)$

${ }^{+}$Within one oil treatment, means are significantly different between day 0 and day 56 (repeated measures; $P \leq 0.05$ ) 
Table 4 Final EPA, DPA, and DHA in plasma, RBC, and PBMC in echium oil vs. linseed oil groups and in control groups after 8-weeks treatment ${ }^{1}$

\begin{tabular}{|c|c|c|c|c|c|}
\hline \multirow[t]{2}{*}{$\%$ of total FAME } & \multirow{2}{*}{$\begin{array}{l}\text { Study } 1 \text { Echium } \\
\text { oil }(n=59)\end{array}$} & \multirow{2}{*}{$\begin{array}{l}\text { Study } 2 \text { Linseed } \\
\text { oil mixture }(n=59)\end{array}$} & \multirow{2}{*}{$\begin{array}{l}\text { Treatment effect } \\
\text { EO vs. LO } P^{2}\end{array}$} & \multicolumn{2}{|l|}{ Control groups } \\
\hline & & & & Fish oil $(n=19)$ & Olive oil $(n=18)$ \\
\hline \multicolumn{6}{|l|}{ Plasma } \\
\hline EPA & $1.63 \pm 0.51^{b}$ & $1.07 \pm 0.36^{c}$ & $<0.001$ & $3.91 \pm 0.99^{a}$ & $0.55 \pm 0.20^{d}$ \\
\hline DPA & $0.72 \pm 0.14^{b}$ & $0.54 \pm 0.11^{c}$ & $<0.001$ & $0.84 \pm 0.23^{\mathrm{a}}$ & $0.43 \pm 0.11^{d}$ \\
\hline $\mathrm{DHA}$ & $1.49 \pm 0.42^{\mathrm{bd}}$ & $1.39 \pm 0.34^{c}$ & 0.009 & $1.93 \pm 0.55^{\mathrm{a}}$ & $1.29 \pm 0.39^{c d}$ \\
\hline \multicolumn{6}{|l|}{ RBC } \\
\hline EPA & $1.51 \pm 0.33^{b}$ & $1.11 \pm 0.31^{c}$ & 0.001 & $2.05 \pm 0.28^{\mathrm{a}}$ & $0.67 \pm 0.23^{d}$ \\
\hline DPA & $2.68 \pm 0.38^{\mathrm{ab}}$ & $2.44 \pm 0.36^{\mathrm{ab}}$ & 0.049 & $2.94 \pm 0.37^{a}$ & $2.07 \pm 0.33^{c}$ \\
\hline $\mathrm{DHA}$ & $3.80 \pm 0.83^{\mathrm{ab}}$ & $3.62 \pm 0.74^{\mathrm{ab}}$ & 0.35 & $4.15 \pm 0.73^{\mathrm{a}}$ & $3.39 \pm 0.89^{b}$ \\
\hline \multicolumn{6}{|l|}{ PBMC } \\
\hline EPA & $0.69 \pm 0.21^{b}$ & $0.54 \pm 0.14^{c}$ & $<0.001$ & $1.91 \pm 0.45^{\mathrm{a}}$ & $0.30 \pm 0.07^{d}$ \\
\hline DPA & $2.37 \pm 0.55^{b}$ & $2.11 \pm 0.37^{c}$ & $<0.001$ & $3.28 \pm 0.38^{\mathrm{a}}$ & $1.68 \pm 0.23^{d}$ \\
\hline $\mathrm{DHA}$ & $1.38 \pm 0.39^{d}$ & $1.53 \pm 0.34^{b}$ & 0.003 & $1.71 \pm 0.28^{\mathrm{ac}}$ & $1.51 \pm 0.33^{b c}$ \\
\hline
\end{tabular}

${ }^{1}$ Values are means $\pm S D$; adjusted means are not shown. EO, echium oil, $L O$ linseed oil mixture, PBMC peripheral blood mononuclear cells, RBC red blood cells. $P$ values were analyzed using the generalized linear mixed model ANCOVA with sex, age, BMI, baseline value as covariates

${ }^{2} P$ values for the treatment effect including only EO and LO groups

${ }^{\mathrm{abc}}$ Means with different superscript letters are significantly different between all treatment groups $(P \leq 0.05)$

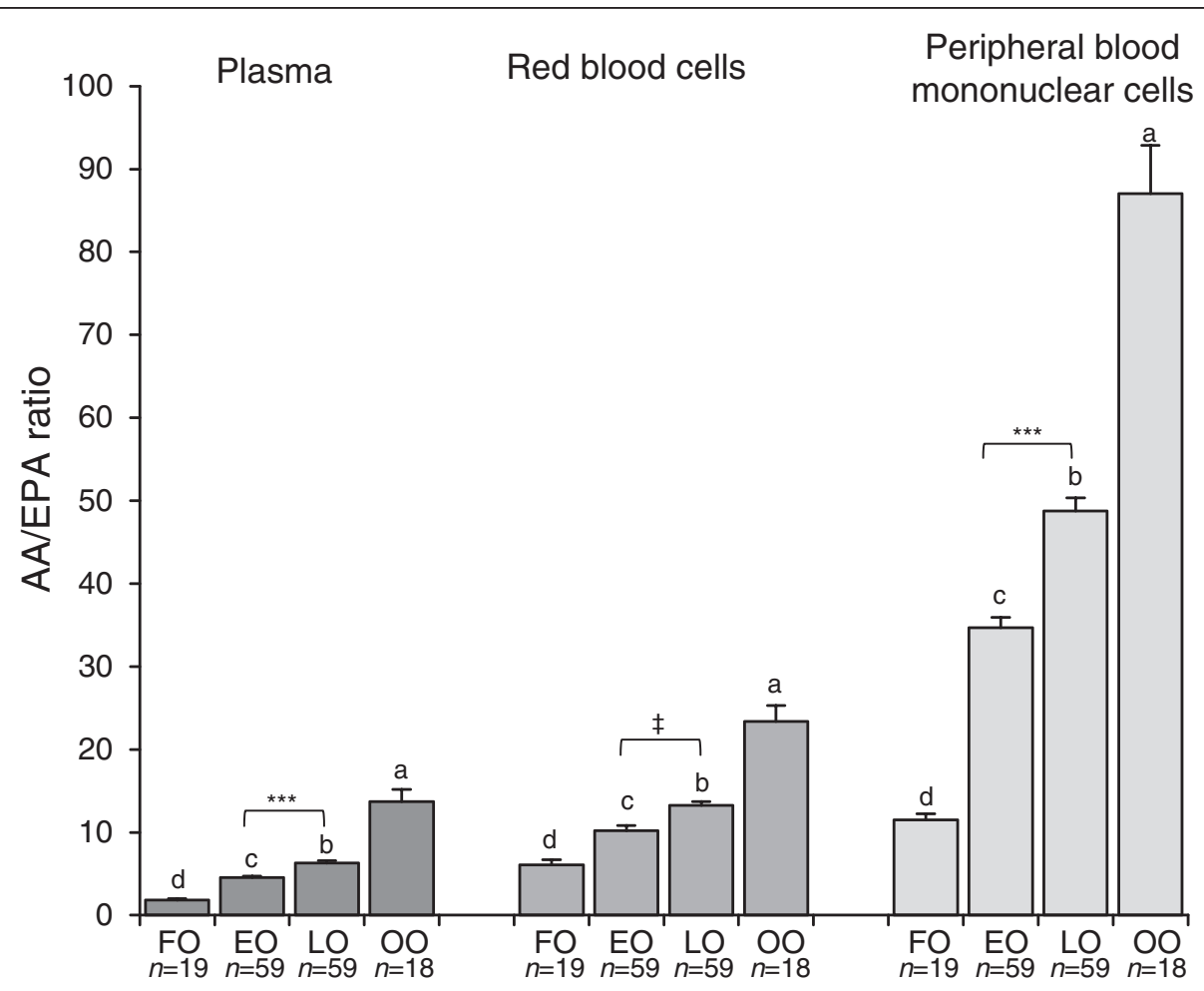

Fig. 2 Final AA/EPA ratio in plasma, RBC, and PBMC in subjects following 8 weeks of fish oil, echium oil, linseed oil mixture, or olive oil. Values are means \pm SEM. $P$ values were analyzed using the generalized linear mixed model ANCOVA with sex, age, BMI, and baseline value as covariates. ${ }^{a b c}$ Within one blood fraction, means with different superscript letters are significantly different between treatment groups $(P \leq 0.05)$. ${ }^{* *}$ Means are significantly different between EO and LO treatment $\left(P<0.001 ;{ }^{\ddagger} P 0.05<0.10\right)$. AA, arachidonic acid; EO, echium oil; FO, fish oil; LO, linseed oil; OO, olive oil 
Table 5 Clinical markers in echium oil and linseed oil groups before and after 8-weeks treatment ${ }^{1}$

\begin{tabular}{|c|c|c|c|c|c|c|}
\hline & & Study 1 Echium oil $(n=59)$ & & Study 2 Linseed oil mixture $(n=59)$ & & Treatment effect EO vs. LO $P^{2}$ \\
\hline \multirow[t]{2}{*}{ Total cholesterol (mmol/L) } & Day 0 & $5.53 \pm 1.25$ & & $5.27 \pm 1.24$ & & \\
\hline & Day 56 & $5.22 \pm 1.17$ & $* * *$ & $5.08 \pm 1.20$ & & 0.59 \\
\hline \multirow[t]{2}{*}{ HDL-C (mmol/L) } & Day 0 & $1.45 \pm 0.38$ & & $1.38 \pm 0.33$ & & \\
\hline & Day 56 & $1.37 \pm 0.42$ & $* * *$ & $1.58 \pm 0.37$ & $* * *$ & $<0.001$ \\
\hline \multirow[t]{2}{*}{ LDL-C (mmol/L) } & Day 0 & $3.33 \pm 0.99$ & & $3.16 \pm 1.03$ & & \\
\hline & Day 56 & $3.03 \pm 0.87$ & $* * *$ & $3.05 \pm 0.99$ & & 0.056 \\
\hline \multirow[t]{2}{*}{ LDL-C/HDL-C } & Day 0 & $2.43 \pm 0.84$ & & $2.38 \pm 0.84$ & & \\
\hline & Day 56 & $2.36 \pm 0.88$ & & $2.00 \pm 0.70$ & $* * *$ & $<0.001$ \\
\hline \multirow[t]{2}{*}{ Triglycerides (mmol/L) } & Day 0 & $1.28 \pm 0.70$ & & $1.22 \pm 0.68$ & & \\
\hline & Day 56 & $1.13 \pm 0.59$ & $* * *$ & $1.12 \pm 0.62$ & & 0.66 \\
\hline \multirow[t]{2}{*}{ Oxidized LDL (mmol/L) } & Day 0 & $80.1 \pm 16.0$ & & $58.9 \pm 17.1$ & & \\
\hline & Day 56 & $75.8 \pm 14.9$ & $* * *$ & $54.0 \pm 17.7$ & * & $<0.001$ \\
\hline \multirow[t]{2}{*}{ Insulin (mU/L) } & Day 0 & $9.07 \pm 5.07$ & & $8.26 \pm 5.26$ & & \\
\hline & Day 56 & $6.25 \pm 4.54$ & $* * *$ & $7.38 \pm 3.69$ & * & 0.011 \\
\hline
\end{tabular}

${ }^{1}$ Values are means \pm SD; adjusted means are not shown. $C$ cholesterol, $E O$ echium oil, $L O$ linseed oil mixture. $P$ values were analyzed using the generalized linear mixed model ANCOVA with sex, age, BMI, baseline value as covariates

${ }^{2} P$ values for the treatment effect including only EO and LO groups

*Within one oil treatment, means are significantly different between day 0 and day 56 (repeated measures; ${ }^{* * *} P \leq 0.001 ;{ }^{*} P \leq 0.05$ )

in the LO group (Table 2). The insulin concentration in serum decreased most with EO vs. LO $(P<0.001)$, while OO remained unchanged (Table 5).

\section{Discussion}

Natural linseed oil contains a high portion of ALA (60-70\%) but little to no SDA [23]. In contrast, due to the high activity of $\Delta 6$-desaturase in Echium species, there are high levels of SDA (10-15 \%) and GLA (8-12\%), the respective conversion products of ALA and LA $[10,11]$. In the present study, the major aim was to investigate the effectiveness of SDA in EO compared to SDA-free LO for increasing endogenous LC n-3 PUFA stores in blood fractions under otherwise equal conditions (e.g. amounts of ALA and LA, n-6/n-3 ratio). Therefore, it was necessary to blend the $\mathrm{LO}$ with further plant oils. In addition, the habitual diet of participants contained no fish and seafood, which meant that there was minimal intake of dietary EPA and DHA.

\section{Increase in EPA and DPA}

Eight weeks of EO supplementation led to a two- to three-fold EPA and DPA increase in plasma and cellular blood fractions compared to that achieved with LO. In one of the first clinical studies investigating SDA metabolism [12], similar quantities of SDA ethyl esters were compared with ALA ( $0.75 \mathrm{~g}$ and $1.5 \mathrm{~g}$ ). The effectiveness of SDA in increasing EPA in plasma and RBC was about four-fold that of ALA [12]. In the present study, similar results were achieved using the natural complex oils (Tables 3 and 4). As the EO and LO supplements provided similar amounts of ALA $(\sim 5 \mathrm{~g})$, it is likely that the additional $2 \mathrm{~g}$ of SDA provided by the EO was responsible for the additional increase in EPA and DPA.

The relative effectiveness of the four tested oils in increasing EPA and DPA in plasma, RBC, and PBMC was 100:25:10:0 and 100:50:25:0 for FO:EO:LO:OO, respectively. Similar results were obtained for the EPA increase in blood when purified ethyl esters of EPA, SDA, and ALA were administered to healthy male and postmenopausal female subjects (100:30:7) [12]. In contrast, in muscle tissue in lambs supplemented with $\mathrm{EO}$ or LO, only slight differences in LC n-3 PUFA were found [24]. As shown in Table 3, with respect to each oil treatment, the different intensities of increase in FA clearly represents the known metabolic pathway of n-3 and n-6 PUFA, as previously reviewed [25]. In general, the increases in EPA and DPA in RBC, considered as middle-to-long-term markers for FA intake and metabolism [26], confirmed that an 8-weeks EO or LO supplementation adequately achieved significant accumulation.

\section{No increase in DHA}

Despite higher EPA and DPA in blood following EO supplementation, no consistently higher DHA could be observed compared to LO. In accordance with previous studies of EO, SDA ethyl esters, and SDA-enriched soybean oil, no increase in plasma, RBC, or PBMC DHA was found following 8 weeks of EO supplementation in this population [12, 15-18]. Previous clinical trials of ALA supplementation from LO ( $\sim 5 \mathrm{~g} / \mathrm{d})$ [27-29] found increases in EPA ( $50 \%)$ with no change in DHA, similar 
to the effects achieved in our study. It is possible that conversion of DPA into DHA, which requires elongation, $\Delta 6$ desaturation, and a final chain shortening by peroxisomal $\beta$-oxidation, is limited by competition with dietary ALA [30]. We hypothesized that EO could compensate a DHA decline better than LO [20]. Surprisingly, the decrease in DHA was not significantly greater in the LO or OO groups compared to EO.

\section{Influencing factors on ALA and SDA conversion}

The metabolism of ALA and also of SDA may be influenced by dietary factors, including amounts of ALA, LA, EPA, DHA, and the n-6/n-3-ratio [20, 28, 31-34]. Reducing the $n-6 / n-3$ ratio in the diet may reduce the risk for CVD, but increasing the absolute amount of LC n-3 PUFA may be more effective [35]. In the present study, the EO and LO supplements provided similar $n-6 / n-3$ and LA/ALA ratios, as well as absolute LA and ALA amounts. However, the EO did provide additional n- 6 GLA, which may have led to greater competition for $\Delta 5$ desaturase and could decrease the efficacy of SDA conversion. Nonetheless, it is likely that the additional GLA was converted into DGLA, which has been also shown with Ahiflower oil ${ }^{\mathrm{Tx}}$, an SDA- and GLA-containing plant oil from the Boraginaceae [36]. DGLA is metabolized to series-1 prostaglandins and thromboxanes that have potent anti-inflammatory and vasodilatory effects [25]. This may account, in part, for some of the beneficial effects of EO. AA, the direct product of DGLA, was only slightly increased. Furthermore, due to enhanced EPA accumulation, the AA/EPA ratio was lower in all blood fractions with EO compared with LO. A reduction in the AA/EPA ratio may have clinical relevance because AAderived eicosanoids tend to be more pro-inflammatory and pro-aggregatory than eicosanoids derived from EPA [35]. It has been proposed that a $75 \%$ reduction in plasma AA/EPA may impart clinically meaningful benefits [34]. In the present study, EO and LO supplementation resulted in 60-70 \% and 40-50\% lower plasma and cellular AA/EPA ratio, respectively, compared to OO.

$\mathrm{n}-3$ PUFA status is influenced by gender [37, 38], age [29, 39], and BMI [39]. In the current study populations, these factors appeared to influence baseline status, but have less effect on net increases of EPA and DPA during EO or LO consumption. In exception, during EO supplementation higher BMI was associated with lower increases of plasma EPA and DPA [20]. It may be possible that the expression and/or activity of enzymes necessary for SDA metabolism, such as elongases and $\Delta 5$-desaturase, are dependent on BMI. In support of this, a recent study comparing the effects of FO, SDA oil, and LO in obese and lean Zucker rats, genotype was a significant predictor for tissue FA composition following treatments [40].
Clinical implications of EO supplementation

With respect to blood lipids/lipoproteins, EO supplementation resulted in more beneficial changes than LO, with the exception of HDL-C. In the majority of previous ALA-intervention studies (3-10 g/d; 6-12 weeks) [27-29, 41-44], no significant changes in plasma cholesterol fractions and TG were observed, despite increased plasma EPA. The known lowering of TG with FO [9] was confirmed with the present study (FO group). EO supplementation reduced TG independently of sex, age, and BMI [20]; however, these effects were not significantly greater than those achieved by LO supplementation. In rats, the TG and TC lowering effects of EO or SDA oil $[19,40]$ were explained by decreasing hepatic TG and TC and by downregulation of hepatic genes involved in FA and TG biosynthesis [19]. The cholesterollowering effect of EO could also be due to naturally occurring phytosterols (analyzed in E. wildpretii [45]), as is assumed for LO [29]. As a decrease in LDL-C and an increase in HDL-C is thought to reduce CVD risk, it is difficult to infer the clinical ramifications of the decrease in both LDL-C and HDL-C following EO supplementation. In contrast, LO supplementation resulted in an HDL-C increase. However, no other clinical studies of LO have found an increase in HDL-C [5, 29, 41, 42], except in non-smoking men [43]. Effects on oxLDL with supplementation of $n-3$ PUFA plant oils are rare. Compared to wheat, LO showed no change of oxLDL [44]. However, we found that both EO and LO reduced oxLDL compared to FO and OO controls.

Results from previous studies indicate that SDA may have novel therapeutic efficacy regarding the development of type 2 diabetes mellitus [46] and several obesity related pathologies [40]. In the present study, overweight adults with parameters of the metabolic syndrome responded to EO with a lower diastolic blood pressure and a reduction in blood lipids and serum insulin [20], which may reduce risk for CVD and type 2 diabetes mellitus $[25,46]$. However, these effects were independent of age and BMI - healthy, normal-weight participants also benefitted from daily EO supplementation (e.g. decreased TG and insulin) [20]. It is widely accepted that EPA and DHA have beneficial effects on CVD [47]. However, the mechanisms by which ALA may exert beneficial health effects remain unclear [reviewed in 4]. To date, there is no high quality evidence to support a beneficial effect of ALA in reducing cardiac and sudden death [47]. Therefore, SDA-containing EO may be more cardioprotective than LO, which only provides ALA, due to greater conversion to EPA.

Limitations of the current project are that EO and LO treatments were investigated in two separate studies at different times (despite the same conditions) and the absence of a younger, overweight subgroup. Furthermore, 
the control groups, planned for FA comparison, were smaller than the EO and LO groups.

\section{Conclusions}

In conclusion, 8 weeks of supplementation with EO produced significantly greater increases in plasma, RBC, and PBMC EPA and DPA, as well as a greater reduction in AA/EPA compared to LO. However, treatment with neither EO nor LO maintained blood DHA status in the absence of fish/seafood consumption. Furthermore, reductions in plasma LDL-C and serum insulin were greater with EO than with LO. Therefore, daily intake of SDA-containing EO is a better alternative than $\mathrm{LO}$ for increasing EPA and DPA in blood.

The studies were registered at www.clinicaltrials.gov as NCT01856179 and NCT0131729.

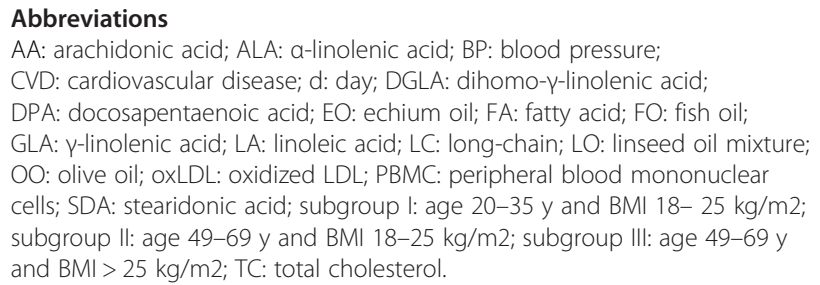

\section{Competing interests}

The authors declare that they have no competing interests.

\section{Authors' contributions}

Design of the study: KK, GJ; conduct of the study: KK, SW, MK; data collection: KK, SW, MK; data analysis: KK, SW, MK; data interpretation: KK, GJ; manuscript writing: KK. All authors read and approved the final manuscript.

\section{Acknowledgements}

The authors thank Cora Richert for conducting the analyses of the biochemical parameters, Ulrich Schäfer and Nasim Krögel for language editing. We thank Frank Staps, Christian Degen, Alfred Lochner, and Carsten Rohrer for technical assistance in FA analyses. We also thank Jens Schumacher from the Institute of Stochastics for the help in the statistical analysis. Furthermore, we are grateful to Beatrice Denk, Melanie Köhler, and Annemarie Grindel for their help during the study and FA analyses.

\section{Financial support}

This project was funded by the German Research Foundation, project K. Kuhnt KU 2584

\section{Author details}

${ }^{1}$ Department of Nutritional Physiology, Institute of Nutrition, Friedrich Schiller University, Dornburger Straße 24, 07743 Jena, Germany. Institute of Clinical Chemistry and Laboratory Medicine, Jena University Hospital, Friedrich Schiller University, Erlanger Allee 101, 07747 Jena, Germany.

\section{Received: 21 August 2015 Accepted: 9 February 2016}

Published online: 18 February 2016

\section{References}

1. Mozaffarian D, Wu JH. Omega-3 fatty acids and CVD: effects on risk factors, molecular pathways, and clinical events. J Am Coll Cardiol. 2011;58:2047-67.

2. Harris WS. The omega-3 index: from biomarker to risk marker to risk factor. Curr Atheroscler Rep. 2009;11:411-7.

3. Kris-Etherton PM, Harris WS, Appel L; American Heart Association. Nutrition Committee. Fish consumption, fish oil, omega-3 fatty acids, and cardiovascular disease. Circulation 2002;106:2747-57.
4. Barceló-Coblijn G, Murphy EJ. Alpha-linolenic acid and its conversion to longer chain n-3 fatty acids: benefits for human health and a role in maintaining tissue n-3 fatty acid levels. Prog Lipid Res. 2009;48:355-74.

5. Brenna JT, Salem Jr N, Sinclair AJ, Cunnane SC, International Society for the Study of Fatty Acids and Lipids, ISSFAL. alpha-Linolenic acid supplementation and conversion to n-3 long-chain polyunsaturated fatty acids in humans. Prostaglandins Leukot Essent Fatty Acids. 2009;80:85-91.

6. Burdge GC, Calder PC. Conversion of alpha-linolenic acid to longerchain polyunsaturated fatty acids in human adults. Reprod Nutr Dev. 2005:45:581-97.

7. Blasbalg TL, Hibbeln JR, Ramsden CE, Majchrzak SF, Rawlings RR. Changes in consumption of omega-3 and omega- 6 fatty acids in the United States during the 20th century. Am J Clin Nutr. 2011;93:950-62.

8. Simopoulos AP. The importance of the omega-6/omega-3 fatty acid ratio in cardiovascular disease and other chronic diseases. Exp Biol Med. 2008;233:674-88.

9. Venegas-Calerón M, Sayanova O, Napier JA. An alternative to fish oils: metabolic engineering of oil-seed crops to produce omega-3 long chain polyunsaturated fatty acids. Prog Lipid Res. 2010;49:108-19.

10. Guil-Guerrero JL. Stearidonic acid (18:4n-3): Metabolism, nutritional importance, medical uses and natural sources. Eur J Lipid Sci Technol. 2007;109:1226-36.

11. Kuhnt K, Degen C, Jaudszus A, Jahreis G. Searching for health beneficial n-3 and n-6 fatty acids in plant seeds. Eur J Lipid Sci Technol. 2012;114:153-60.

12. James MJ, Ursin VM, Cleland LG. Metabolism of stearidonic acid in human subjects: comparison with the metabolism of other $\mathrm{n}-3$ fatty acids. Am J Clin Nutr. 2003;77:1140-5.

13. Ruiz-Lopez N, Haslam RP, Venegas-Caleron M, Larson TR, Graham IA, Napier JA, Sayanova O. The synthesis and accumulation of stearidonic acid in transgenic plants: a novel source of 'heart-healthy' omega-3 fatty acids. Plant Biotechnol J. 2009;7:704-16.

14. Harris WS. Stearidonic acid-enhanced soybean oil: a plant-based source of (n-3) fatty acids for foods. J Nutr. 2012;142:600S-4

15. Harris WS, Lemke SL, Hansen SN, Goldstein DA, DiRienzo MA, Su H, Nemeth MA, Taylor ML, Ahmed G, George C. Stearidonic acid-enriched soybean oil increased the omega-3 index, an emerging cardiovascular risk marker. Lipids. 2008:43:805-11.

16. Lemke SL, Vicini JL, Su H, Goldstein DA, Nemeth MA, Krul ES, Harris WS. Dietary intake of stearidonic acid-enriched soybean oil increases the omega-3 index: randomized, double-blind clinical study of efficacy and safety. Am J Clin Nutr. 2010;92:766-75.

17. Krul ES, Lemke SL, Mukherjea R, Taylor ML, Goldstein DA, Su H, Liu P. Lawless A, Harris WS, Maki KC. Effects of duration of treatment and dosage of eicosapentaenoic acid and stearidonic acid on red blood cell eicosapentaenoic acid content. Prostaglandins Leukot Essent Fatty Acids. 2012;86:51-9.

18. Surette ME, Edens M, Chilton FH, Tramposch KM. Dietary echium oil increases plasma and neutrophil long-chain (n-3) fatty acids and lowers serum triacylglycerols in hypertriglyceridemic humans. J Nutr. 2004;134:1406-11.

19. Zhang P, Boudyguina E, Wilson MD, Gebre AK, Parks JS. Echium oil reduces plasma lipids and hepatic lipogenic gene expression in apoB100-only LDL receptor knockout mice. J Nutr Biochem. 2008;19:655-63.

20. Kuhnt K, Fuhrmann C, Köhler M, Kiehntopf M, Jahreis G. Dietary echium oil increases long-chain n-3 PUFA including docosapentaenoic acid in blood fractions and alters biochemical markers for CVD independent of age, sex, and metabolic syndrome. J Nutr. 2014;144:447-60.

21. Grindel A, Staps F, Kuhnt K. Cheek cell fatty acids reflect n-3 PUFA in blood fractions during linseed oil supplementation: a controlled human intervention study. Lipids Health Dis. 2013;12:173.

22. Kuhnt K, Kraft J, Moeckel P, Jahreis G. Trans-11-18:1 is effectively Delta9desaturated compared with trans-12-18:1 in humans. Br J Nutr. 2006;95:752-61.

23. Dubois V, Breton S, Linder M, Fanni J, Parmentier M. Fatty acid profiles of 80 vegetable oils with regard to their nutritional potential. Eur J Lipid Sci Technol. 2007:109:710-32

24. Kitessa SM, Young P, Nattrass G, Gardner G, Pearce K, Pethick DW When balanced for precursor fatty acid supply echium oil is not superior to linseed oil in enriching lamb tissues with long-chain n-3 PUFA. Br J Nutr. 2012:108:71-9.

25. Poudyal H, Panchal SK, Diwan V, Brown L. Omega-3 fatty acids and metabolic syndrome: effects and emerging mechanisms of action. Prog Lipid Res. $2011 ; 50: 372-87$ 
26. Arab L. Biomarkers of fat and fatty acid intake. J Nutr. 2003;133 Suppl 3:925S-32.

27. Finnegan YE, Minihane AM, Leigh-Firbank EC, Kew S, Meijer GW, Muggli R, Calder PC, Williams CM. Plant- and marine-derived $\mathrm{n}-3$ polyunsaturated fatty acids have differential effects on fasting and postprandial blood lipid concentrations and on the susceptibility of LDL to oxidative modification in moderately hyperlipidemic subjects. Am J Clin Nutr. 2003;77:783-95.

28. Dewell A, Marvasti FF, Harris WS, Tsao P, Gardner CD. Low- and high-dose plant and marine (n-3) fatty acids do not affect plasma inflammatory markers in adults with metabolic syndrome. J Nutr. 2011;141:2166-71.

29. Patenaude A, Rodriguez-Leyva D, Edel AL, Dibrov E, Dupasquier CM, Austria $J$ A, Richard MN, Chahine MN, Malcolmson LJ, Pierce GN. Bioavailability of alpha-linolenic acid from flaxseed diets as a function of the age of the subject. Eur J Clin Nutr. 2009;63:1123-9.

30. Portolesi R, Powell BC, Gibson RA. Competition between 24:5n-3 and ALA for Delta 6 desaturase may limit the accumulation of DHA in HepG2 cell membranes. J Lipid Res. 2007;48:1592-8.

31. Vermunt SHF, Mensink RP, Simonis MMG, Hornstra G. Effects of dietary alpha-linolenic acid on the conversion and oxidation of C-13-alpha-linolenic acid. Lipids. 2000;35:137-42.

32. Goyens P, Spilker M, Zock P, Katan M, Mensink R. Conversion of alphalinolenic acid in humans is influenced by the absolute amounts of alphalinolenic acid and linoleic acid in the diet and not by their ratio. Am J Clin Nutr. 2006;84:44-53.

33. Emken EA, Adlof RO, Gulley RM. Dietary linoleic acid influences desaturation and acylation of deuterium-labeled linoleic and linolenic acids in young adult males. Biochim Biophys Acta. 1994;1213:277-88.

34. Gillingham LG, Harding SV, Rideout TC, Yurkova N, Cunnane SC, Eck PK, Jones PJ. Dietary oils and FADS1-FADS2 genetic variants modulate [13C]alinolenic acid metabolism and plasma fatty acid composition. Am J Clin Nutr. 2013;97:195-207.

35. Stanley JC, Elsom RL, Calder PC, Griffin BA, Harris WS, Jebb SA, Lovegrove JA, Moore CS, Riemersma RA, Sanders TA. UK Food Standards Agency Workshop Report: the effects of the dietary n-6:n-3 fatty acid ratio on cardiovascular health. Br J Nutr. 2007;98:1305-10.

36. Surette ME. Dietary omega-3 PUFA and health: stearidonic acid-containing seed oils as effective and sustainable alternatives to traditional marine oils. Mol Nutr Food Res. 2013:57:748-59.

37. Childs CE, Romeu-Nadal M, Burdge GC, Calder PC. Gender differences in the n-3 fatty acid content of tissues. Proc Nutr Soc. 2008;67:19-27.

38. Burdge G. Alpha-linolenic acid metabolism in men and women: nutritional and biological implications. Curr Opin Clin Nutr Metab Care. 2004;7:137-44

39. Sands SA, Reid KJ, Windsor SL, Harris WS. The impact of age, body mass index, and fish intake on the EPA and DHA content of human erythrocytes. Lipids. 2005:40:343-7.

40. Casey JM, Banz WJ, Krul ES, Butteiger DN, Goldstein DA, Davis JE. Effect of stearidonic acid-enriched soybean oil on fatty acid profile and metabolic parameters in lean and obese Zucker rats. Lipids Health Dis. 2013;12:147.

41. Barceló-Coblijn G, Murphy EJ, Othman R, Moghadasian MH, Kashour T, Friel JK. Flaxseed oil and fish-oil capsule consumption alters human red blood cell $n-3$ fatty acid composition: a multiple-dosing trial comparing 2 sources of n-3 fatty acid. Am J Clin Nutr. 2008;88:801-9.

42. Kaul N, Kreml R, Austria JA, Richard MN, Edel AL, Dibrov E, Hirono S, Zettler ME, Pierce GN. A comparison of fish oil, flaxseed oil and hempseed oil supplementation on selected parameters of cardiovascular health in healthy volunteers. J Am Coll Nutr. 2008;27:51-8.

43. Sioen I, Hacquebard M, Hick G, Maindiaux V, Larondelle Y, Carpentier YA, De Henauw S. Effect of ALA-enriched food supply on cardiovascular risk factors in males. Lipids. 2009;44:603-11.

44. Bloedon LT, Balikai S, Chittams J, Cunnane SC, Berlin JA, Rader DJ, Szapary PO. Flaxseed and cardiovascular risk factors: results from a double-blind, randomized, controlled clinical trial. J Am Coll Nutr. 2008;27:65-74.

45. Santana O, Reina M, Braulio MF, Sanz J, Gonzalez-Coloma A. Antifeedant activity of fatty acid esters and phytosterols from Echium wildpretii. Chem Biodivers. 2012;9:567-76.

46. Banz WJ, Davis JE, Clough RW, Cheatwood JL. Stearidonic acid: is there a role in the prevention and management of type 2 diabetes mellitus? J Nutr. 2012;142:635S-40.

47. Wang C, Harris WS, Chung M, Lichtenstein AH, Balk EM, Kupelnick B, Jordan HS, Lau J. n-3 Fatty acids from fish or fish-oil supplements, but not alpha-linolenic acid, benefit cardiovascular disease outcomes in primary- and secondaryprevention studies: a systematic review. Am J Clin Nutr. 2006;84:5-17.

\section{Submit your next manuscript to BioMed Central and we will help you at every step:}

- We accept pre-submission inquiries

- Our selector tool helps you to find the most relevant journal

- We provide round the clock customer support

- Convenient online submission

- Thorough peer review

- Inclusion in PubMed and all major indexing services

- Maximum visibility for your research

Submit your manuscript at www.biomedcentral.com/submit
(O) BioMed Central 